\title{
The effects of opioids on HIV reactivation in latently-infected T-lymphoblasts
}

\author{
Johannes Prottengeier ${ }^{1 *}$, Eleni Koutsilieri ${ }^{2}$ and Carsten Scheller ${ }^{2}$
}

\begin{abstract}
Background: Opioids may have effects on susceptibility to HIV-infection, viral replication and disease progression. Injecting drug users (IDU), as well as anyone receiving opioids for anesthesia and analgesia may suffer the clinical consequences of such interactions. There is conflicting data between in vitro experiments showing an enhancing effect of opioids on HIV replication and clinical data, mostly showing no such effect. For clarification we studied the effects of the opioids heroin and morphine on HIV replication in cultured CD4-positive T cells at several concentrations and we related the observed effects with the relevant reached plasma concentrations found in IDUs.

Methods: Latently-infected ACH-2 T lymphoblasts were incubated with different concentrations of morphine and heroine. Reactivation of HIV was assessed by intracellular staining of viral Gag p24 protein and subsequent flow cytometric quantification of p24-positive cells. The influence of the opioid antagonist naloxone and the antioxidants $\mathrm{N}$-acetyl-cysteine (NAC) and glutathione (GSH) on HIV reactivation was determined. Cell viability was investigated by 7-AAD staining and flow cytometric quantification.
\end{abstract}

Results: Morphine and heroine triggered reactivation of HIV replication in ACH-2 cells in a dose-dependent manner at concentrations above $1 \mathrm{mM}$ (EC 50 morphine $2.82 \mathrm{mM}$; $\mathrm{EC}_{50}$ morphine $1.96 \mathrm{mM}$ ). Naloxone did not interfere with heroine-mediated HIV reactivation, even at high concentrations (1 mM). Opioids also triggered necrotic cell death at similar concentrations at which HIV reactivation was observed. Both opioid-mediated reactivation of HIV and opioid-triggered cell death could be inhibited by the antioxidants GSH and NAC.

Conclusions: Opioids reactivate HIV in vitro but at concentrations that are far above the plasma levels of analgesic regimes or drug concentrations found in IDUs. HIV reactivation was mediated by effects unrelated to opioid-receptor activation and was tightly linked to the cytotoxic activity of the substances at millimolar concentrations, suggesting that opioid-mediated reactivation of HIV was due to accompanying effects of cellular necrosis such as activation of reactive oxygen species and NF-KB.

Keywords: HIV, Reactivation, Opioids, Heroine, Morphine, Naloxone, ACH-2

\section{Introduction}

Many of the HIV-infected individuals who inject intravenous drugs consume morphine, heroin or related substances. There is conflicting data on the impact of opioids on HIV disease progression. Whereas in vitro studies suggest a potential link between opioid exposure and elevated virus replication or decreased immune function [1-5], most of epidemiological and clinical studies do not find a correlation between opioid intake and progression of HIV infection [6-12]. In order to reconcile these conflicting

\footnotetext{
* Correspondence: Johannes.Prottengeier@kfa.imed.uni-erlangen.de

'Department of Anesthesiology, Erlangen University Hospital,

Krankenhausstrasse 12, 91054 Erlangen, Germany

Full list of author information is available at the end of the article
}

data, we performed in vitro experiments studying the effects of opioids (heroin and morphine) on HIV replication in the chronically-infected CD4-positive T cell line ACH-2 [13]. CD4-positive $\mathrm{T}$ cells represent the cellular reservoir in which HIV is harbored predominantly in the body and they contribute to most of the viral replication detected in the blood plasma [14-16].

\section{Results}

Morphine and heroine reactivate HIV in ACH-2 cells In order to investigate the effects of the opioids heroine and morphine on reactivation of proviral HIV in latentlyinfected T cells, we incubated ACH-2 cells with different 
concentrations of morphine-sulfate and heroine. After incubation for $24 \mathrm{~h}$ we measured intracellular HIV-p24 protein expression by flow cytometry. We found a dosedependent reactivation of HIV for morphine (Figure 1A) and heroine (Figure 1B). The $\mathrm{EC}_{50}$ concentrations for the two substances were $2.82 \mathrm{mM}$ and $1.96 \mathrm{mM}$, respectively (Figure 1). Figures $1 \mathrm{C}$ and $\mathrm{D}$ display representative dot-plots analyzing p24-expression (y-axis) of untreated (Figure $1 \mathrm{C}$ ) or $4 \mathrm{mM}$ heroin-treated (D) cells. The background expression visible in Figure $1 \mathrm{C}$ is typical for $\mathrm{ACH}-$ 2 cells and originates from intrinsic stimulation of the cells. We also tested the effects of heroin on HIV replication at very low concentrations, similar to the plasma concentrations found in IDUs and found no activating effects (Figure 1D).

\section{Naloxone does not inhibit heroine-mediated reactivation of HIV}

Opioid receptor signaling has been described on lymphocytes [1] and opioid receptors that bind the opioid antagonist naloxone have been identified on $\mathrm{T}$ cells (reviewed in [17]). We therefore investigated whether the observed HIV-activating effect of opioids was mediated by opioidspecific receptor stimulation. For that we triggered HIV reactivation with heroine in the absence or presence of different concentrations of naloxone. As depicted
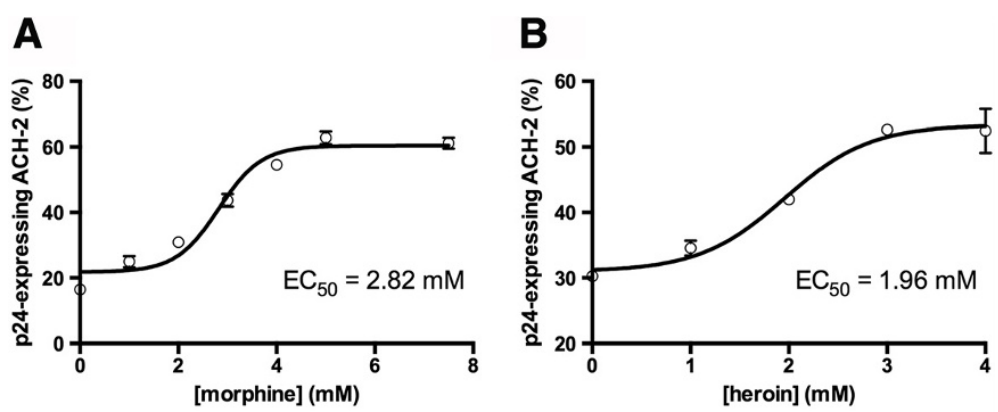

C

D
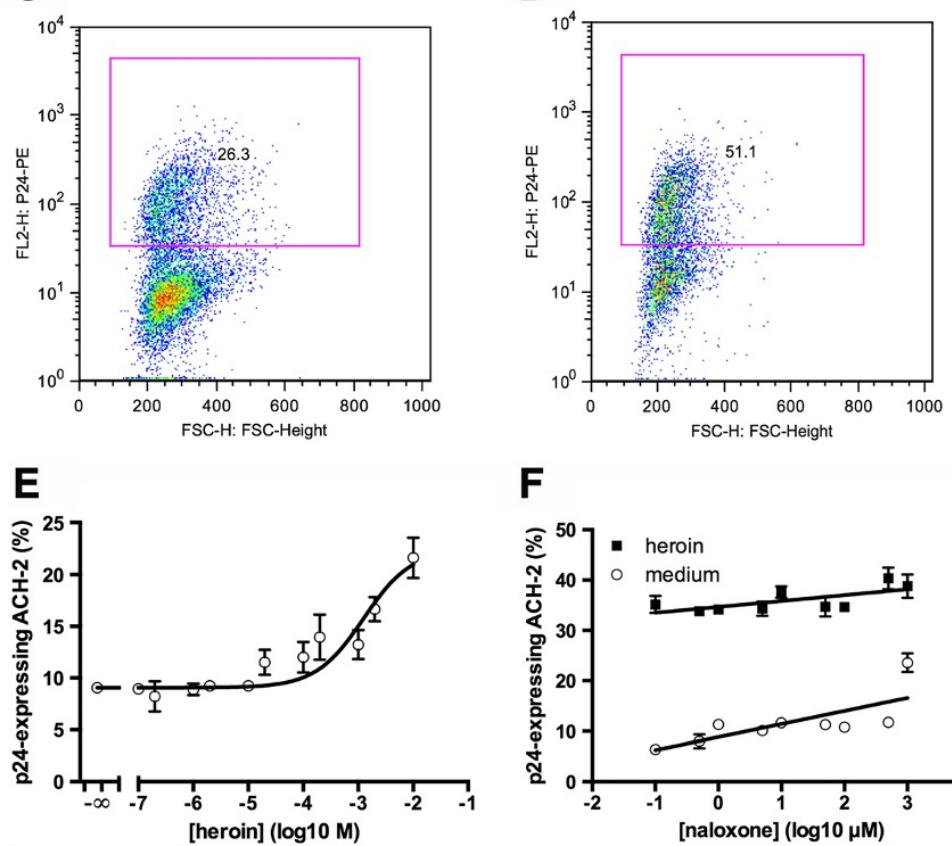

$\mathbf{F}$

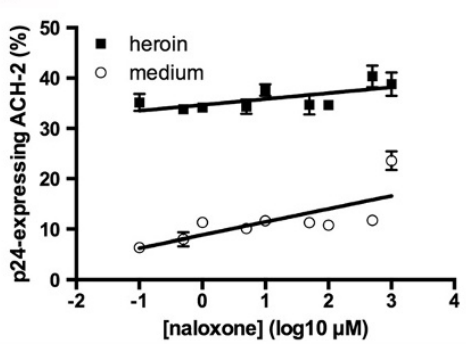

Figure 1 Opioids activate HIV replication in vitro. Latently-HIV-infected ACH-2 T lymphoblasts were cultured for 24 hours in the presence of different concentrations of morphine (A) or heroin (B). HIV replication was quantified by intracellular staining of HIV p24-antigen and flow cytometry. C, D: representative dot-plot analyses of ACH-2 cells left untreated (C) or treated with $4 \mathrm{mM}$ heroin (D). The x-axis displays the forward scatter, the $y$-axis displays p24-expression. Pink rectangles represent the gates for p24-positive cells and the small numbers within indicate the proportion (\%) of p24-positive cells from the total number of events. E: Heroin has no effects on HIV reactivation at concentrations found in plasma of IDUs (1-10 $\mu \mathrm{M})$. F: Latently-HIV-infected ACH-2 T lymphoblasts were cultured for 24 hours in the presence of $5 \mathrm{mM}$ heroin, together with different concentrations of naloxone $(0 \mu \mathrm{M}$ and $0.1 \mu \mathrm{M}-1 \mathrm{mM})$. HIV replication was quantified by intracellular staining of HIV p24-antigen and flow cytometry. Data as mean \pm S.E.M. from duplicates and linear regression. The slopes of both regressions are positive and significantly differ from $=$ zero ( $p=0.0008$ for medium and $p=0.0152$ for heroin). 
in Figure $1 \mathrm{~F}$, naloxone did not interfere with heroinemediated HIV reactivation, indicating that opioid receptorindependent mechanisms account for the observed effects.

\section{NAC and GSH inhibit opioid-mediated HIV reactivation}

Heroin- and morphine-mediated activation of HIV replication was completely prevented by the antioxidants $\mathrm{N}$-acetylcystein (NAC) or reduced glutathione (GSH) (Figure 2), indicating that oxidative stress might be involved in opioid-mediated reactivation of HIV. The relatively high opioid concentrations needed to stimulate HIV replication were also associated with induction of necrotic cell death. A3.01 T cells, the uninfected parental cell line of $\mathrm{ACH}-2$ cells, showed a significant amount of necrosis induction following treatment with $2.5 \mathrm{mM}$ heroin as assessed by staining with the cell dye 7-AAD (Figure 3A). This necrosis induction could again be completely prevented by the antioxidant $\mathrm{N}$-acetylcystein (Figure 3A). We used for this experiment the uninfected parental cell line because the 7-AAD dye requires nonfixated cells, which in case of the HIV-infected ACH-2 cells we could not subject to our flow cytometer for safety reasons. In order to demonstrate that $\mathrm{ACH}-2$ cells react in a similar way to opioids as A3.01 cells, we analyzed cell death in ACH-2 cells by a characteristic shift of the cell population in the forward-scatter/sideward-scatter dot plot analysis, which correlates with 7-AAD-staining. This shift is depicted in Figure $3 \mathrm{C}$ from representative analyses for different heroin concentrations. The corresponding p24-expression profiles are depicted in Figure 3D. As shown in Figure 3B, activation of HIV in ACH-2 cell completely paralleled with opioid-triggered necrosis. We reported earlier that necrotic signaling triggers NF- $\mathrm{kB}$ and HIV-reactivation in ACH-2 T lymphoblasts [18]. These data indicate that the observed opioid-mediated activation of HIV replication was secondary to the opioid-triggered necrosis observed at high concentrations.

\section{Discussion}

Opioid-mediated reactivation of latent HIV infection in our model was observed at concentrations in the lower millimolar range. Since opioids are common in the HIVrisk group of injecting drug users (IDUs), this activity might influence the pathogenesis of HIV infection in this group of patients. However, plasma concentrations of heroine in IDUs are in the range of $1-10 \mu \mathrm{M}$ [19] and even maximum plasma concentrations are only in the range of $1500-3900 \mathrm{ng} / \mathrm{ml}$ (reviewed in [20]), which corresponds to 4.1-10.7 $\mu \mathrm{M}$ (calculated with a molar weight of $369.41 \mathrm{~g} / \mathrm{mol}$ ). Secondly plasma-concentrations of medically administered morphine and its modern derivates for means of analgesia remain well below those ranges of reactivating effects [21-23]. These in vivo concentrations are 2-3 orders of magnitude lower than the in vitro concentration at which we observed a stimulating effect. It therefore seems very unlikely that the heredescribed opioid-mediated reactivation of HIV may have any influence on HIV replication in vivo.

Opioid-triggered reactivation of HIV replication in latently-infected cells has been described in the monocytic cell line U1 [3]. HIV reactivation after treatment with morphine was observed in the picomolar $\left(10^{-12}\right)$
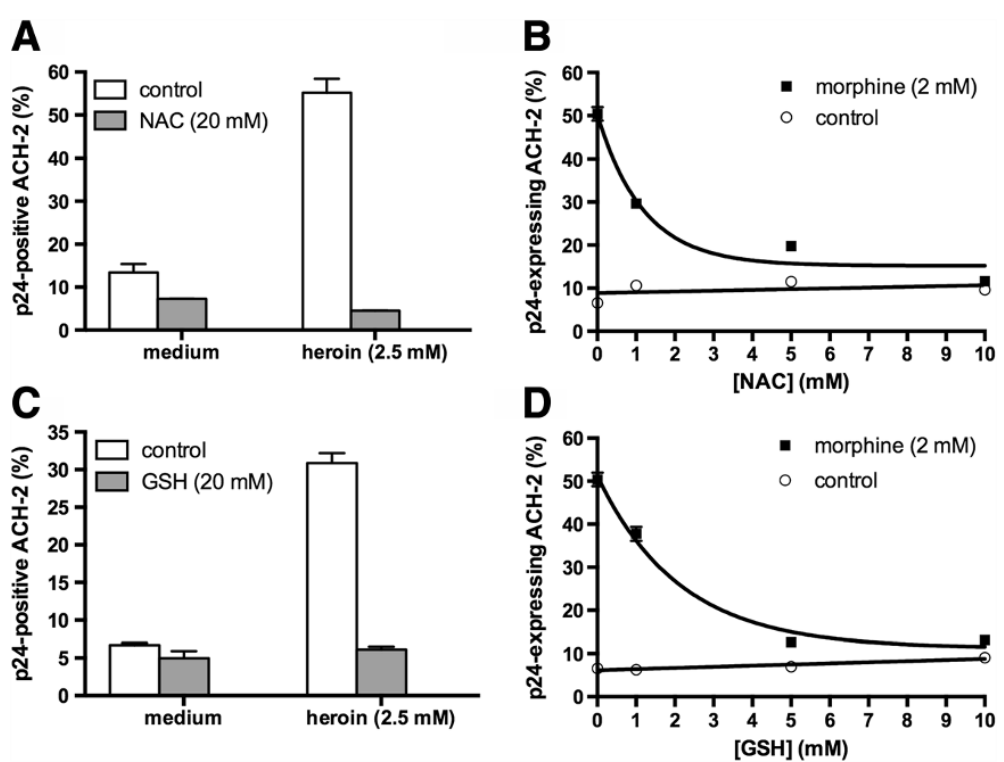

Figure 2 Antioxidants inhibit opioid-mediated reactivation of HIV. Latently-HIV-infected ACH-2 T lymphoblasts were cultured for 24 hours with of heroin (A, C) or morphine (B, D) in the presence or absence of the antioxidants N-acetylcystein (NAC) (A, B) or glutathione (C, D). HIV replication was quantified by intracellular staining of HIV p24-antigen and flow cytometry. 
A

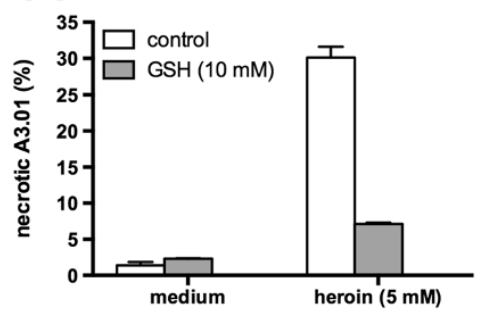

C cell viability
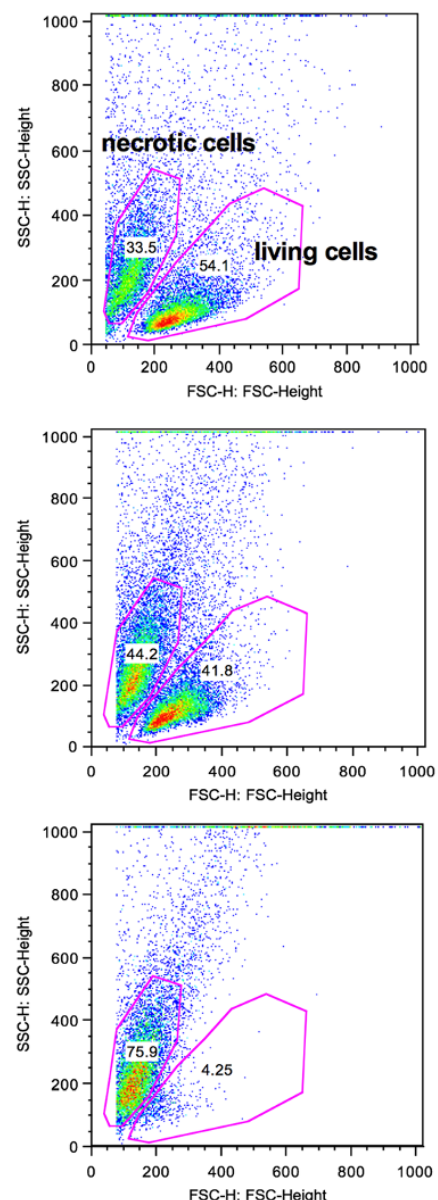

B

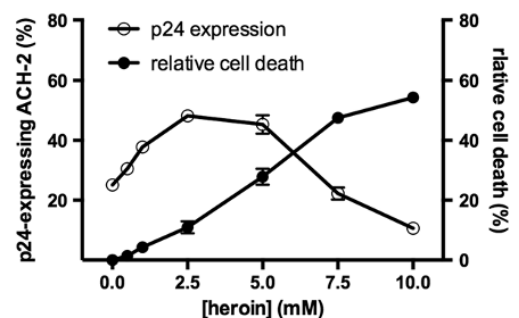

D p24 expression
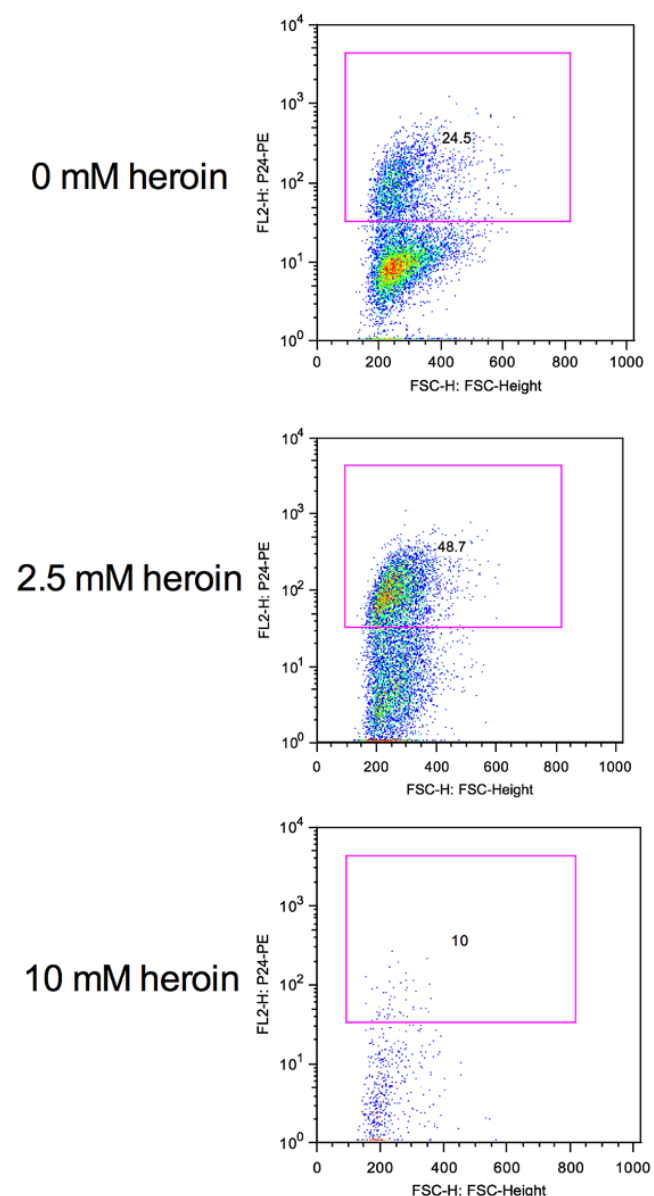

Figure 3 Opioid-mediated reactivation of HIV is tightly linked to cellular necrosis. Latently-HIV-infected ACH-2 T lymphoblasts were cultured for 24 hours with of heroin in the presence or absence of glutathione. HIV replication was quantified by intracellular staining of HIV p24-antigen and flow cytometry (A). Cell viability was assessed by FSC/SSC-analysis in flow cytometry (B). Representative dot plots of cell viability analysis (C) and p24-expression (D) at different heroin concentrations. Pink rectangles on the right represent the gates for p24-positive cells and the small numbers within indicate the proportion (\%) of p24-positive cells from the total number of events. Pink regions on the left represent the gates for living and necrotic cells and the small numbers within indicate the proportion (\%) of events within the region from the total number of events.

range but not at higher concentrations. Especially at micromolar concentrations - the concentration range of plasma levels found in drug abusers - no effects were observed [3]. Similar effects were reported from the same group when studying productive infection in cultured peripheral blood lymphocytes [4]. In studies with experimental SHIV-infection in the rhesus macaque model, elevated viral load was reported in morphinetreated animals $(n=6)$ versus untreated animals $(n=3)$ [2]. Recently, a decrease in anti-HIV microRNA expression was reported in monocytes following treatment with morphine and heroin [5], suggesting a potential 
explanation for the increased viral replication found in in vitro studies.

In contrast, the majority of epidemiological studies does not show negative effects of drug abuse on HIV progression [8-12], but many confounding variables such as the pattern of drug use may make it difficult to clearly interpret this data. To address this, a prospective clinical study with a total of 1148 participants was performed, in which the effects of hard drug use (opioids or cocaine) on HIV disease parameters was studied [6]. Drug use had no effect on HIV viral load or CD4 cell counts $(n=613$ versus $n=$ 535). In line with this, no effects of drug use on viral load have been observed in a seroconverter study with 60 injection drug users in a total of 149 participants [7].

The literature therefore seems to be divided into experimental and in vitro studies reporting enhancement of HIV infection following treatment with opioids and in vivo studies not finding such a correlation. We suggest that this difference, at least in parts, relates to the concentration range at which effects were observed: All in vitro studies reporting an HIV-activating effect of opioids in cell culture found these effects at very low concentrations and no activity was observed at relevant plasma concentrations [3-5]. Moreover, all so-far reported in vitro data were generated in monocytes [3,5] (or in PBMC containing monocytes [4]), whereas more than $99 \%$ of HIV particles detected in the human plasma originate from $\mathrm{T}$ lymphocytes $[15,24,25]$. Hence, effects found in monocytes in vitro may not be representative for the lymphocytedriven plasma viral load in vivo. Our in vitro-results indicate that there is an HIV-stimulating effect of opioids also in $\mathrm{T}$ cells, but only at concentrations that are far above relevant in vivo-concentrations. The molecular mechanism of HIV latency in the ACH-2 cell line used in our study is caused by a defect in the Tat/TAR axis [26] and the same mechanism of latency is also frequently found in latentlyinfected primary T cells isolated from HIV patients [27].

Taken together, the literature seems to be divided into in vitro studies reporting enhancement of HIV infection following treatment with opioids and in vivo studies not finding such a correlation. Our in-vitro results indicate that there is an HIV-stimulating effect of opioids in latently-infected $\mathrm{T}$ cells, but only at concentrations that are far beyond relevant in vivo-concentrations and our findings may therefore contribute to reconcile the apparently conflicting data of in vitro and in vivo research. Our data provides no evidence that the medical use of opioids for indications of anesthesia and analgesia in HIV-infected patients may have any side effects on HIV replication.

\section{Conclusion}

Opioids reactivate HIV in vitro but at concentrations that are far above the plasma levels of analgesic regimes or drug concentrations found in IDUs. HIV reactivation is mediated by effects unrelated to opioid-receptor activation and seems tightly linked to the cytotoxic activity of these substances at a millimolar level, suggesting that opioid-mediated reactivation of HIV is due to accompanying effects of cellular necrosis such as activation of reactive oxygen species and NF- $\mathrm{kB}$.

\section{Materials and methods \\ Cell culture}

A3.01 (human CD4 + -T-lymphoblasts, NIAID) and ACH-

2 (latently HIV-infected A3.01, Folks 1989, NIAID) were cultured in standard tissue flasks using RPMI-medium (Invitrogen, Karlsruhe, Germany) supplemented with 10\% FCS (Linaris, Bettingen, Germany) at $37^{\circ} \mathrm{C}$ and $5 \% \mathrm{CO} 2$ atmosphere. Peripheral blood mononuclear cells (PBMC) were isolated by Ficoll/Paque density-separation centrifugation from human whole blood donated by healthy volunteers. For the different experiments $10^{5}$ cells per well were cultured in flat-bottom 96 well plates in a total volume of $200 \mu \mathrm{l}$ for $24 \mathrm{~h}$ in the absence or presence of the indicated substances.

\section{Opioids, antagonists and other reagents}

Morphine and Heroine were obtained from the University of Wurzburg's Department of Forensic Medicine. The Use and Discard of those substances were documented in accordance with the German Narcotics Act. Naloxone, Glutathion and N-Acetylcysteine were purchased through Sigma, St.Lewis, MO.

\section{Flow cytometry}

Reactivation of HIV in ACH-2 cells was quantified by the expression of viral p24-antigen detected by flow cytometry (Becton-Dickinson, Heidelberg, Germany). Cells were fixated for 20 min with $4 \%$ formalin in PBS and later permeabilized with $0.5 \%$ saponin in PBS/5\%BSA. The following antibodies were used: 183-H12-5C-anti-HIV-p24-mouseantibody and goat-anti-mouse antibodies conjugated with FITC or PE (BD Biosciences). Cell death in uninfected A3.01 cells was quantified by 7-AAD staining according to the instructions of the manufacturer (BD Biosciences). Besides staining with 7-AAD, necrotic cells also displayed a characteristic shift in a forward-scatter (FSC)/sideward scatter (SSC) dot plot. This shift was used to quantify necrotic cells also for HIV-infected ACH-2 cells, for which a 7-AAD staining was not possible for safety reasons (7-AAD staining requires nonfixated cells which in case of $\mathrm{ACH}-2$ cells would contaminate the flow cytometer with HIV).

Competing interests

All of the authors declare that they have no competing interests.

Authors' contributions

CS conceived of the study and helped to draft the manuscript. JP conducted the study, performed the statistical analysis and is the main author of the 
manuscript. EK participated in the study's design and helped to draft the manuscript. All authors read and approved the final manuscript.

\section{Acknowledgements}

We thank Ingeborg Euler-König for excellent technical assistance. The following agents were obtained through National Institutes of Health - AIDS Research and Reference Reagent Program: $\mathrm{A} 3.01$ and $\mathrm{ACH}-2$ cells by T. Folks; p24-HIV-Hybridoma (183-H12-5C) by B.Chesebro and H.Chen. The study was supported by a grant from the Bundesministerium für Bildung und Forschung (BMBF $01 \mathrm{Kl}$ 9479).

\section{Author details}

'Department of Anesthesiology, Erlangen University Hospital, Krankenhausstrasse 12, 91054 Erlangen, Germany. ${ }^{2}$ Institute of Virology and Immunobiology, University of Würzburg, Würzburg, Germany.

Received: 5 June 2014 Accepted: 28 June 2014

Published: 2 July 2014

\section{References}

1. Nair MP, Schwartz SA, Polasani R, Hou J, Sweet A, Chadha KC: Immunoregulatory effects of morphine on human lymphocytes. Clin Diagn Lab Immunol 1997, 4(2):127-132.

2. Perez-Casanova A, Husain K, Noel RJ Jr, Rivera-Amill V, Kumar A: Interaction of SIV/SHIV infection and morphine on plasma oxidant/antioxidant balance in macaque. Mol Cell Biochem 2008, 308(1-2):169-175.

3. Peterson PK, Gekker G, Hu S, Anderson WR, Kravitz F, Portoghese PS, Balfour $\mathrm{HH} \mathrm{Jr}$, Chao CC: Morphine amplifies HIV-1 expression in chronically infected promonocytes cocultured with human brain cells. J Neuroimmunol 1994, 50(2):167-175.

4. Peterson PK, Sharp BM, Gekker G, Portoghese PS, Sannerud K, Balfour HH Jr: Morphine promotes the growth of HIV-1 in human peripheral blood mononuclear cell cocultures. AIDS 1990, 4(9):869-873.

5. Wang X, Ye L, Zhou Y, Liu MQ, Zhou DJ, Ho WZ: Inhibition of anti-HIV microRNA expression: a mechanism for opioid-mediated enhancement of HIV infection of monocytes. Am J Pathol 2011, 178(1):41-47.

6. Thorpe LE, Frederick M, Pitt J, Cheng I, Watts DH, Buschur S, Green K, Zorrilla C, Landesman SH, Hershow RC: Effect of hard-drug use on CD4 cell percentage, HIV RNA level, and progression to AIDS-defining class C events among HIV-infected women. J Acquir Immune Defic Syndr 2004, 37(3):1423-1430.

7. Lyles CM, Dorrucci M, Vlahov D, Pezzotti P, Angarano G, Sinicco A, Alberic F, Alcorn TM, Vella S, Rezza G: Longitudinal human immunodeficiency virus type 1 load in the italian seroconversion study: correlates and temporal trends of virus load. J Infect Dis 1999, 180(4):1018-1024.

8. Prins $\mathrm{M}$, Veugelers PJ: Comparison of progression and non-progression in injecting drug users and homosexual men with documented dates of HIV-1 seroconversion. European Seroconverter Study and the Tricontinental Seroconverter Study. AIDS 1997, 11(5):621-631.

9. Biggar RJ: AIDS incubation in 1891 HIV seroconverters from different exposure groups. International Registry of Seroconverters. AIDS 1990, 4(11):1059-1066.

10. Spijkerman IJ, Langendam MW, Veugelers PJ, van Ameijden EJ, Keet IP, Geskus RB, van den Hoek A, Coutinho RA: Differences in progression to AIDS between injection drug users and homosexual men with documented dates of seroconversion. Epidemiology 1996, 7(6):571-577.

11. Carre N, Deveau C, Belanger F, Boufassa F, Persoz A, Jadand C, Rouzioux C, Delfraissy JF, Bucquet D: Effect of age and exposure group on the onset of AIDS in heterosexual and homosexual HIV-infected patients. SEROCO Study Group. AIDS 1994, 8(6):797-802.

12. Pehrson $P$, Lindback S, Lidman C, Gaines $H$, Giesecke J: Longer survival after HIV infection for injecting drug users than for homosexual men: implications for immunology. AIDS 1997, 11(8):1007-1012

13. Folks TM, Clouse KA, Justement J, Rabson A, Duh E, Kehrl JH, Fauci AS: Tumor necrosis factor alpha induces expression of human immunodeficiency virus in a chronically infected T-cell clone. Proc Natl Acad Sci U S A 1989, 86(7):2365-2368.

14. Psallidopoulos MC, Schnittman SM, Thompson LM 3rd, Baseler M, Fauci AS, Lane HC, Salzman NP: Integrated proviral human immunodeficiency virus type 1 is present in CD4+ peripheral blood lymphocytes in healthy seropositive individuals. J Virol 1989, 63(11):4626-4631.
15. Schnittman SM, Psallidopoulos MC, Lane HC, Thompson L, Baseler M, Massari F, Fox CH, Salzman NP, Fauci AS: The reservoir for HIV-1 in human peripheral blood is a T cell that maintains expression of CD4. Science 1989, 245(4915):305-308

16. McElrath MJ, Pruett JE, Cohn ZA: Mononuclear phagocytes of blood and bone marrow: comparative roles as viral reservoirs in human immunodeficiency virus type 1 infections. Proc Natl Acad Sci U S A 1989, 86(2):675-679.

17. Sharp BM: Multiple opioid receptors on immune cells modulate intracellular signaling. Brain Behav Immun 2006, 20(1):9-14.

18. Scheller C, Sopper S, Chen P, Flory E, Koutsilieri E, Racek T, Ludwig S, ter Meulen $V$, Jassoy C: Caspase inhibition activates HIV in latently infected cells. Role of tumor necrosis factor receptor 1 and CD95. J Biol Chem 2002, 277(18):15459-15464

19. Rook EJ, Huitema AD, van den Brink W, van Ree JM, Beijnen JH: Population pharmacokinetics of heroin and its major metabolites. Clin Pharmacokinet 2006, 45(4):401-417.

20. Rook EJ, Huitema AD, van den Brink W, van Ree JM, Beijnen JH: Pharmacokinetics and pharmacokinetic variability of heroin and its metabolites: review of the literature. Curr Clin Pharmacol 2006, 1(1):109-118.

21. Martini C, Olofsen E, Yassen A, Aarts L, Dahan A: Pharmacokineticpharmacodynamic modeling in acute and chronic pain: an overview of the recent literature. Expert Rev Clin Pharmacol 2011, 4(6):719-728.

22. Lotsch J: Pharmacokinetic-pharmacodynamic modeling of opioids. J Pain Symptom Manage 2005, 29(5 Suppl):S90-S103.

23. Zollner C, Schafer M: [Opioids in anesthesia]. Anaesthesist 2008, 57(7):729-740. quiz 741-722.

24. Perelson AS, Neumann AU, Markowitz M, Leonard JM, Ho DD: HIV-1 dynamics in vivo: virion clearance rate, infected cell life-span, and viral generation time. Science 1996, 271(5255):1582-1586.

25. Ho DD, Neumann AU, Perelson AS, Chen W, Leonard JM, Markowitz M: Rapid turnover of plasma virions and CD4 lymphocytes in HIV-1 infection. Nature 1995, 373(6510):123-126.

26. Emiliani S, Van Lint C, Fischle W, Paras P Jr, Ott M, Brady J, Verdin E: A point mutation in the HIV-1 Tat responsive element is associated with postintegration latency. Proc Natl Acad Sci U S A 1996, 93(13):6377-6381.

27. Yukl S, Pillai S, Li P, Chang K, Pasutti W, Ahlgren C, Havlir D, Strain M, Gunthard H, Richman D, Rice AP, Daar E, Little S, Wong JK: Latently-infected CD4+ T cells are enriched for HIV-1 Tat variants with impaired transactivation activity. Virology 2009, 387(1):98-108.

doi:10.1186/1742-6405-11-17

Cite this article as: Prottengeier et al:: The effects of opioids on HIV reactivation in latently-infected T-lymphoblasts. AIDS Research and Therapy 2014 11:17.

\section{Submit your next manuscript to BioMed Central and take full advantage of:}

- Convenient online submission

- Thorough peer review

- No space constraints or color figure charges

- Immediate publication on acceptance

- Inclusion in PubMed, CAS, Scopus and Google Scholar

- Research which is freely available for redistribution 